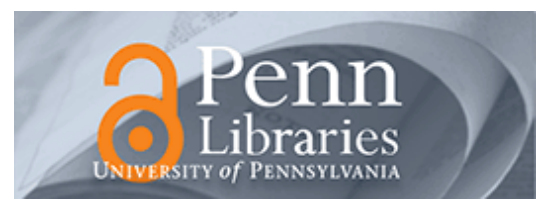

University of Pennsylvania

ScholarlyCommons

Operations, Information and Decisions Papers

Wharton Faculty Research

2-2001

\title{
Selecting R\&D Projects at BMW: A Case Study of Adopting \\ Mathematical Programming Models
}

Christoph. H. Loch

Michael. T. Christian

Christian Terwiesch

University of Pennsylvania

Michael Urbschat

Follow this and additional works at: https://repository.upenn.edu/oid_papers

Part of the Mathematics Commons

\section{Recommended Citation}

Loch, C. H., Christian, M. T., Terwiesch, C., \& Urbschat, M. (2001). Selecting R\&D Projects at BMW: A Case Study of Adopting Mathematical Programming Models. IEEE Transactions on Engineering Management, 48 (1), 70-80. http://dx.doi.org/10.1109/17.913167

This paper is posted at ScholarlyCommons. https://repository.upenn.edu/oid_papers/228

For more information, please contact repository@pobox.upenn.edu. 


\title{
Selecting R\&D Projects at BMW: A Case Study of Adopting Mathematical Programming Models
}

\author{
Abstract \\ Research and development (R\&D) project selection is a critical interface between the product \\ development strategy of an organization and the process of managing projects day-to-day. This article \\ describes the project selection problem faced by an R\&D group of BMW (Munich, Germany). The problem \\ was structured as minimizing the gap between target performance of the technology to be developed and \\ actual performance of the current technology along chosen criteria. A mathematical programming model \\ helped this organization to increase the transparency of their selection process, which previously had \\ been based on experience coupled with evaluation of individual projects in isolation Implementation was \\ a success in that the predevelopment group continues to use the model to make better decisions. \\ However, the organization did not use the model for its intended purpose: constrained optimization. The \\ traditional explanation for this partial implementation is that the analytical model did not capture all \\ considerations relevant to optimization (e.g., uncertainty or strategic fit), and that further model \\ refinements are required to achieve further implementation. We offer an alternative explanation, one \\ based on the technology transfer literature. The diffusion of the analytical model from academia to \\ industry faced the same problems as any technology transfer: Significant tacit knowledge had to be \\ transferred along with the codified knowledge of the analytical model. This required iterated problem \\ solving, which required the limited time and resources of the diffusing agents (academia) as well as the \\ adopting agents (industry). Thus, the organization adopted only those elements of the modeling method \\ that could be transferred within the resource constraints, focusing on those elements offering the highest \\ benefit per effort invested. \\ Disciplines
Mathematics
}

This journal article is available at ScholarlyCommons: https://repository.upenn.edu/oid_papers/228 


\title{
Selecting R\&D Projects at BMW: A Case Study of Adopting Mathematical Programming Models
}

\author{
Christoph H. Loch ${ }^{*}$, Michael T. Pich ${ }^{*}$, Christian Terwiesch ${ }^{* *}$, Michael Urbschat $^{* * *}$
}

September 1999

\begin{abstract}
R\&D project selection is a critical interface between the product development strategy of an organization and the process of managing projects day-to-day. This article describes the project selection problem faced by the transmission pre-development group of BMW. The group had to choose a portfolio of projects to set the foundation for the "best powertrain 2000." This problem of project selection was structured as minimizing the gap between target performance and actual performance along chosen criteria. A mathematical programming model helped this organization to increase the transparency of their selection process, which previously had been based on experience coupled with evaluation of individual projects in isolation. The model was used to structure data collection, to apply to consistent criteria to the selection of pre-development projects, and to compare weighted project benefits. Implementation was a success in that the pre-development group continues to use it to make better decisions.
\end{abstract}

However, the organization did not use the model for constrained optimization. We see two reasons for this partial implementation of the model. First, an analytical model cannot capture all considerations relevant to optimization (e.g., uncertainty or strategic fit). Thus, constrained optimization promised only marginal further benefits while requiring substantial additional effort. Second, the diffusion of the analytical model from academia to industry faced the same problems as any technology transfer: Significant tacit knowledge must be transferred along with the codified knowledge of the analytical model. This required iterated problem solving, which itself required the limited time and resources of the diffusing agents (academia) as well as the adopting agents (industry). Thus, the organization adopted only those elements of the modeling method that could be transferred within the resource constraints, focusing on those elements offering the highest benefit per effort invested.

Keywords: R\&D, project selection, mathematical programming, analytical models, technology transfer, gatekeeper, tacit knowledge, process of OR, pre-development, automotive industry.

\footnotetext{
* INSEAD, Boulevard de Constance, 77305 Fontainebleau, France

** Wharton School, University of Pennsylvania, Philadelphia PA 19104, USA.

BMW AG, 80788 Munich, Germany

The authors thank two anonymous referees for helpful comments on an earlier draft of this paper.
} 


\section{Introduction}

Project selection is a critical management activity in research and development (R\&D) organizations. It allocates resources to and sets priorities among R\&D programs that will determine the future business mix of a company (Roussel et al. 1991, Cooper et al. 1997). It thus provides a critical link between the goals of an organization's new product development (NPD) strategy and the activities of its NPD process.

Because project selection can involve a multitude of interdependent decisions in complex circumstances, it has provided researchers fertile ground to develop highly structured, model-based decision support tools (cf, Beged-Dov 1965). This research stream has offered a wide variety of analytical methods for choosing R\&D projects to meet strategic objectives. However, the modelers involved in this research stream have, for a long time now, complained that their proposed approaches are not widely adopted in practice (Souder 1978, Schmidt and Freeland 1992, Cabral-Cardoso and Payne 1996, Burnett et al. 1993). This has typically justified further attempts to improve (and publish) these analytical models to better meet the perceived needs of industry. Although this activity has greatly advanced the sophistication of these analytical models, it has done little to increase their adoption by those for whom they are designed to benefit (Hall and Nauda 1990).

Literature on the practice of Operations Research (OR) recognizes that the implementation of analytical methods should follow a structured process (cf, Corbett and Van Wassenhove 1993), and often requires the focal organization to change in multiple directions at the same time. It is, therefore, not surprising that this process often fails (Mitchell 1993, p. 183). In this paper we extend current explanations for the lack of diffusion of such models by drawing on the extant literature of technology transfer. We argue that by doing so we can shed further light on the process of developing and implementing quantitative methods of $R \& D$ project selection, which leads to higher chances of adoption.

Specifically, we present a case study of the introduction of one such analytical project selection method into an R\&D organization, namely the transmission predevelopment group at BMW. This R\&D subunit faced the challenge of pre-developing new technologies and improvements to existing technologies to provide the technological foundation for the "best powertrain 2000." They started by identifying 80 candidate projects among which a choice had to be made. The problem was identified as one of selecting a subset of the 80 projects to minimize the total gap between target and current product performance while not exceeding the limited resources available to the predevelopment group. This problem structure was an ideal candidate for implementation of a mathematical programming model of project selection. Thus, the authors developed a mixed- 
integer program for project selection and worked with the predevelopment group to implement it for the "best powertrain 2000."

Four important lessons for researchers and managers of $R \& D$ emerge from this case study:

1. We present a quantitative model of $R \& D$ project selection along with a description of how this model was implemented in an actual R\&D organization. The detailed description of framework development, data collection and joint problem solving can help interested readers to adapt the model to their own R\&D organization.

2. Consistent with previous findings in the literature, the model was used to structure data collection, to apply consistent criteria to the selection of pre-development projects, and to compare weighted project benefits. This allowed the R\&D subunit to make the project selection process more transparent and fact-based.

3. The quantitative model was only partially adopted by the organization. The resource-constrained optimization feature of the model was never fully understood or utilized. Two reasons for this partial adoption behavior are explored.

i. The first reason is consistent with previous research in this area in that it recognizes that the analytical model was incomplete and failed to capture adequately all possible aspects of the problem - for example, uncertainty, risk behavior, or strategic fit. Therefore, constrained optimization promised only marginal further benefits while requiring substantial additional effort, the organization made an economic decision to adopt only those elements of the modeling method offering the highest benefit per effort invested. Under this reasoning, future improvements to the modeling methodology could lead to further adoption.

ii. The second reason draws from the technology transfer literature. Full adoption would have required significant additional resources and time from both the adopting organization and the diffusing agents, yet both had only limited resources available to attend to the transfer. The partial adoption of the technology had as much to do with the limited time window of the diffusing agents as it did with the limited resources of the adopting organization.

4. During the implementation process, the importance of "boundary spanners" became apparent in introducing, filtering and diffusing the new method into the organization. This refers to those individuals who span the "gap" between the R\&D subunit and external sources of innovation, or between the R\&D subunit and other subunits within the organization.

In the remainder of this article, we first review the relevant literature on project selection and technology transfer, and then describe in turn the starting point of the organization, the process of introducing the new method, results obtained, management of resistance, and reasons for not using the method as an optimization tool. We conclude 
with a discussion of the insights to be had from drawing from the extant literature on technology transfer and the diffusion of innovations.

\section{Literature: Project Selection and Technology Transfer}

In this work, we draw on two streams of research. The first is a large body of work addressing the question of how to select product development projects. The second is related to technology transfer in general, and specifically the transfer and implementation of operations research models.

\section{$2.1 R \& D$ Project Selection}

Within the project selection work, we see three relevant sub-streams. The first emphasizes the connection of innovation projects to strategy, illuminating issues of risk balance and strategic complementarity of the portfolio (c.f. Krogh et al. 1988, Roussel et al. 1991, Wheelwright and Clark 1992, Cooper et al. 1997). These approaches are very useful for assessing the strategic impact of a portfolio of major development undertakings. They are, however, only qualitative and restricted to an aggregate level of analysis. They cannot easily be used for concrete decisions at the level of individual development projects.

The second sub-stream consists of the standard decision theory methodology, applicable on the operational level of individual projects. It consists of ranking projects according to a number of weighted decision criteria and then picking the best ones. This is the most widely used in practice (cf, Brenner 1994). As decision weights are difficult to define and often contested by different parties involved, the most common methodology is to collapse the decision problem corresponding to a single project into a single financial number, such as net present value (NPV) (Hess 1993; Sharpe and Keelin, 1998) or break-even time (BET) (House and Price 1991). Alternatively, the analytical hicrarchy proccss offers a method for structuring and justifying multiple critcria (Liberatore 1987, Brenner 1994). All these methods share the drawback that neither uncertainty nor interactions among projects— that is, among those competing for the same scarce resources—can be captured.

A third sub-stream of work within project selection literature, based on mathematical programming models, has long been proposed to optimize the selection of projects in portfolios (Beged-Dov 1965, Benson et al. 1993, Schmidt and Freeland 1992, Souder 1973 and 1978). A special powerful feature of these models is their ability to include interactions among projects. Examples for such interactions are competition for the same resource pool, system level interactions through mutual incompatibilities, syner- 
gistic enhancements or project "enablers," or market interactions if the market criteria are not separable and additive (Fox et al. 1984). Czajkowski and Jones (1986) describe how some of the above-mentioned types of interactions can be represented in a mixed integer linear program, based on an application in the aerospace industry. The operational analysis may also be embedded into a hierarchical filter, where projects not fitting the strategic mission are eliminated prior to detailed portfolio selection by the mathematical programming model (Yap and Souder 1993). Mathematical programs can also incorporate risk by including sensitivity analysis and probabilistic violations of constraints (Czajkowski and Jones 1986), but the capability of incorporating risk is limited (Fox et al. 1984, Souder 1978).

Although this stream of work has yielded successful examples of project portfolio selection under many different problem-specific circumstances, the resulting analytical models have yet to be widely adopted by practitioners (Souder 1978, Schmidt and Freeland 1992, Burnett et al. 1993, Cabral-Cardoso and Payne 1996). One classic form of response to this phenomenon has been to improve the modeling methodology. A1though this has lead to great advances in model formulation and analysis, it has done little to spread the adoption of such models. Another response has been to recognize that too much effort is being spent on increasing the sophistication of the models and not enough on the means by which they are understood and adopted by their intended audience (Hall and Nauda 1990). It has been suggested that the greatest value to be had from quantitative modeling efforts is the "managerial insight" gained from such models (c.f. Fortuin et al. 1992, Corbett and Van Wassenhove 1993). This managerial insight is more likely to be gained in the process of transfer than from the actual implementation of the model.

\subsection{Technology Transfer}

We suggest that the implementation of operations research models is not unlike the transfer of many other technologies and thus, one can learn from the extant literature on technology transfer. This literature describes, sometimes in conflicting terms, the importance of strong and weak ties in the diffusion of innovations. Weak ties, defined as distant and infrequent relationships between individuals, offer access to sources of nonredundant information (Granovetter 1973; Hansen, 1999). Gatekeepers (Allen and Cohen, 1969) or boundary spanners (Galbraith, 1973; Tushman, 1977) play an important role in the adoption and diffusion of new methods by spanning several organizational interfaces both within and external to the organization. These weak ties yield opportunities to spot innovative technologies that can be brought into the organization.

However, the product innovation literature also suggests that strong ties, close and frequent interaction between individuals, are necessary for effective technology transfer 
(Clark and Fujimoto, 1991; Leonard-Barton and Sinha, 1993; Henderson and Cockburn, 1994; Eisenhart and Tabrizi, 1995; Szulanski, 1996). While codified information might be useful in some cases of technology transfer, critical aspects of the innovation may remain tacit and difficult to impart (Nelson and Winter 1982, Winter 1987). Significant interactions between the diffusing agent and the potential adopter may be needed to resolve the ambiguity surrounding an innovation and to actually implement it (Arrow 1969). Thus, both the potential adopter and the diffuser of a complex innovation will have to invest resources (notably manpower) that are temporarily unavailable for other, possibly more important activities.

\section{The Case Study}

In this section, we describe the project selection project that we carried out in cooperation with the powertrain predevelopment group at BMW. The pre-development group was responsible for bringing technology components-here, transmission components - to the point of technical maturity where they could be incorporated into vehicle development. A senior R\&D management committee, as a rule, then decided whether or not the series development group would develop the concepts proposed by the predevelopment group. However, sometimes vehicle development picked up ideas directly from external suppliers or other R\&D sub-units within the organization, such as corporate research.

The predevelopment group had been charged with the strategic mission of proposing and developing the "best powertrain 2000." They asked the authors to assist them with their choice among 80 transmission development project ideas that had been collected recently in response to this mission. Of the 80 candidates, 10 represented new technologies, such as a continuously variable transmission, while the others were improvements of existing transmission subsystems.

\subsection{Prior Method of Project Selection}

In the recent past, project selection within the predevelopment group had mainly been based on intuition and the evaluation of individual projects in isolation. Engineers had a feeling for what constituted a "good" transmission and what tradeoffs had to be made in design. There was no established process, and projects were often driven more by personality and initiative, than by any explicit weighing of the tradeoffs among projects. This level of personal involvement was and still is widely perceived as a "strength" within the company.

Under the previous manager, members of the pre-development group normally decided 
among themselves which projects to pursue, based on their experience. If it was within the regular budget, the pre-development group could choose whatever they wanted. If an additional budget was needed, a presentation to upper management had to be made.

This proved good for motivation, but no systematic discussion of the tradeoffs, or competition among projects occurred within the group. Only at the transfer of concepts from pre-development to series development did official committees come into play-possibly up to the board level, depending on the resources involved. These committees applied sets of criteria-for example, noise or handling considerations-that often seemed to appear unexpectedly to the predevelopment engineer involved.

Questions such as "Why did you not consider $x$ and $y$ ?" would arise without a satisfactory reply from the predevelopment engineer involved. For example, a concept might be great for fuel efficiency, and then somebody would drive a prototype and say "Well, it's fuel-efficient but I don't like it because it makes noise and costs too much." And then the concept just died. Indeed, many of the concepts proposed by pre-development died this way. This, of course, caused significant frustration for both the predevelopment engineers and for the development group responsible for introducing new drive trains into the market.

\subsection{Developing a Systematic Selection Methodology}

When responsibility for the pre-development group was transferred to a manager who came from outside of the transmission-engineering unit, he felt uncomfortable with the selection practice that was in place for three reasons. First, he did not have the same level of experience as his predecessor, and so, felt he needed a transparent way to utilize the expertise of his engineers. He could not generate "gut feel" evaluations himself the way his predecessor had. Second, there was feedback from other departments that pre-development's "hit-rate" - that is, its ability to identify components that were eventually implemented in the vehicle-was perceived as being too low. Less than $50 \%$ of the new transmission technologies developed by the unit were actually adopted and implemented in new vehicle development projects. Third, resources were expended on candidate projects without having a clearly stated reason, and these resources needed to be better utilized.

Having come from within the company, the new manager understood and appreciated the need to allow some projects to be driven purely by personal initiative and desire. Thus, he asked himself how many decisions could be made in an "objective way," and concluded that one could spend $20 \%$ of resources on proposals driven by individual initiatives, but $80 \%$ should be spent on "objectively justified projects." 
He began by asking himself two very pragmatic questions: "Where do we spend our money?" and "What are our needs?" Starting with these questions, he defined a list of requirements and collected a list of potential projects together with his experienced project managers. Quickly, the group produced a matrix of evaluation criteria and candidate projects. Examples of criteria are driving dynamics (contribution of the transmission to vehicle acceleration), economy (fuel consumption), fun and comfort of the driver inter-face (e.g., controls and design of the shift lever), cost (development and manufacturing), and dimensions and weight. Examples of projects included improvements to current technologies, such as a new gear set, and entirely new technologies, such as a continuously variable belt drive transmission.

Figure 1 presents a subset of the decision criteria as well as a subset of projects by transmission subsystem, in the same format used by the predevelopment group. Each box in a project row represents the contribution of the project to the target criteria, with '+' and '++', respectively, denoting weak and strong contributions, while '-' and '--' denote weak and strong negative impacts on target criteria. However, the matrix by itself is not sufficient for making a concrete decision. The matrix can identify dominance (superiority on all criteria), but cannot compare projects with different strengths and weaknesses across criteria.

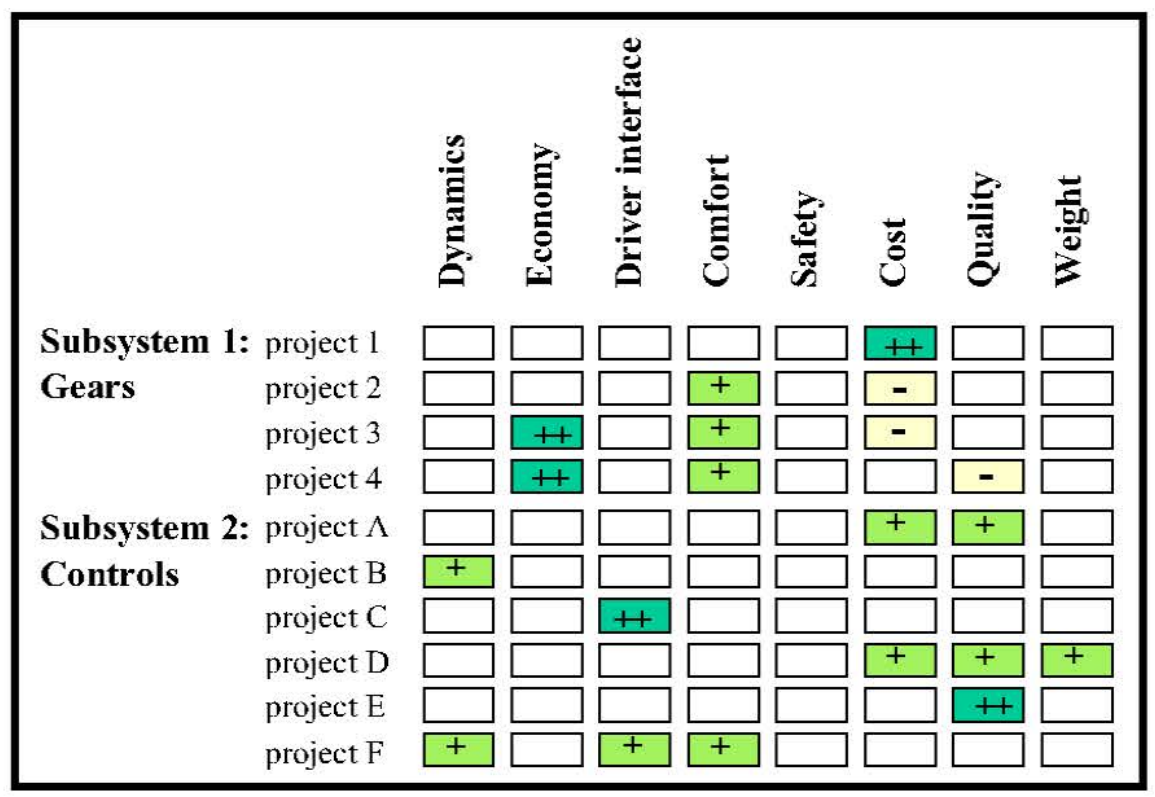

Figure 1: Previous Ranking Approach

\subsection{Introduction of the Analytical Project Selection Method}

At this point, the manager discussed the problem with one of the authors with whom he regularly interacted in a different context. The possibility emerged of obtaining access 
to an additional resource to look at the problem, and of getting feedback from an outsider who would say "I've read a lot about this" or "I've spoken to other engineering companies in this kind of arena" and telling him whether or not he was on the right track.

After several discussions among the authors and the manager, a view of the problem emerged as one of covering a performance shortfall - that is, the gap between a quantified estimate of required, or "target" product performance corresponding to the "best powertrain" and current product performance. The means to cover this "gap" were provided by the candidate project proposals. This approach implied that both the gap and the "contributions" of the candidate projects had to be quantified. In addition, the resource requirements of the projects in terms of development capacity needed to be estimated because resources were scarce.

Based on this structured problem formulation, an analytical approach could be developed in the form of a mixed-integer linear programming model. Figure 2 summarizes the structure of the model. (The mathematical programming formulation is included in the appendix.) The target criteria appear along the top, with each column in the matrix corresponding to a performance dimension. For each criterion, a gap to target was identified, where reaching the target meant establishing a leading position. The gap-totarget estimates were normalized from 0 (no gap) to $100 \%$ (large gap). This ensured compatibility across the criteria. The list of projects appears to the left, with each row corresponding to a candidate project. In the matrix of project contributions, each element reflects the contribution of the project (row) to narrowing the target gap (column).

Binary decision variables for each project indicate whether it was chosen (1) or not $(0)$. If a project is chosen, it consumes resources, with the resulting resource consumption shown on the right. There is a total resource constraint, in person-years, reflecting the development capacity in the group. The capacity constraint corresponds to the predevelopment capacity over three years, a planning horizon consistent with that utilized by the development team and of sufficient length to complete any of the projects. ${ }^{1}$ The resulting total target contributions and the remaining gaps are shown at the bottom of the matrix. Project interactions are indicated at the bottom left. Only system interactions were identified-that is, incompatible projects that could not be implemented within the same system.

A more detailed analysis incorporating scheduling each project and synchronizing the schedule with the strategic plan of vehicle introductions into the market was judged as possible, but of low importance for the purpose of the current selection problem. 


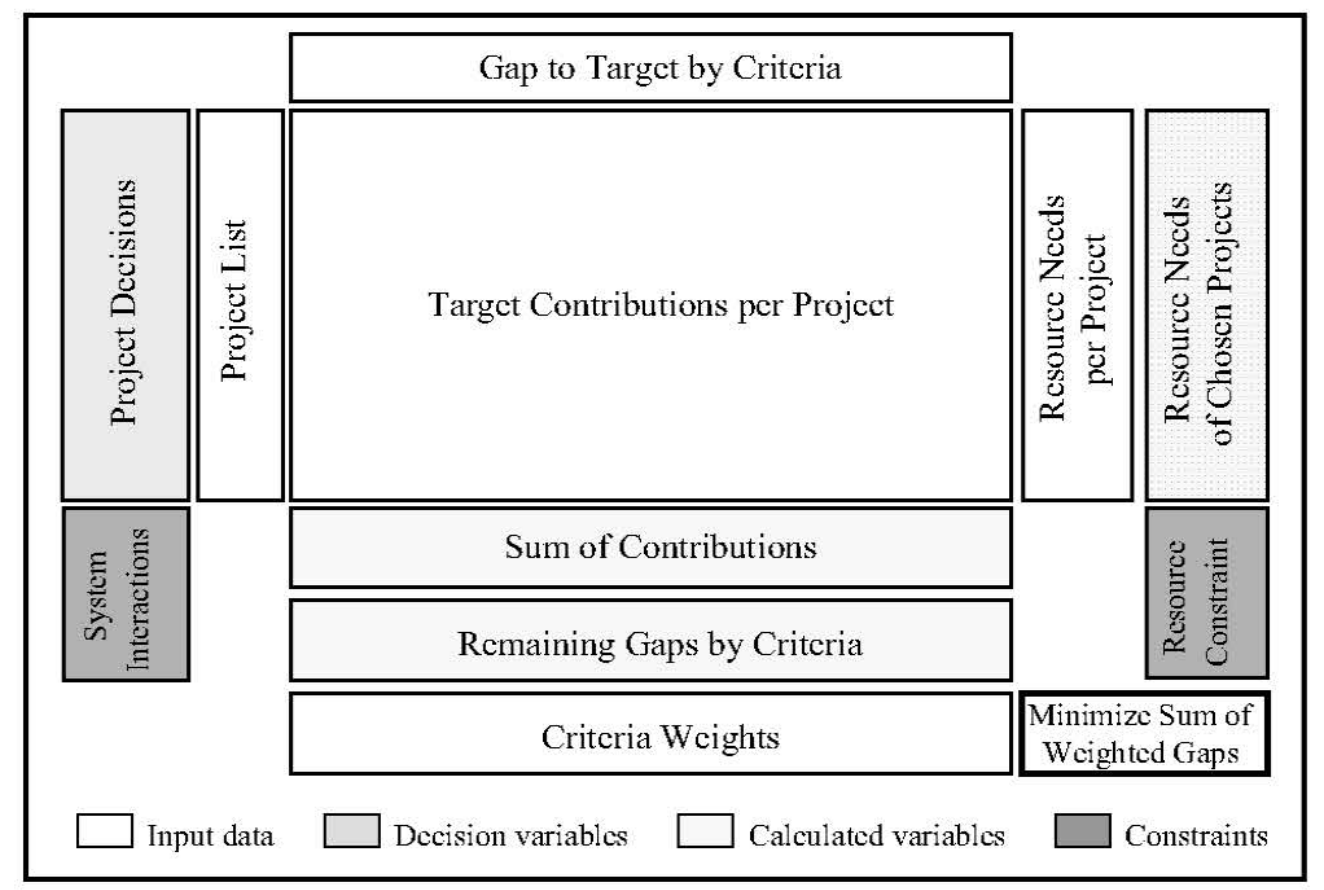

Figure 2: Model Structure

Any target shortfalls, or performance gaps remaining after all resources are consumed by the chosen projects are weighted by the importance of each criterion and summed over all criteria. The objective of the model is to find the project portfolio that minimizes the sum of the weighted shortfalls without violating the resource capacity and system interaction constraints. The model allows "overshoot," or over-fulfillment of a target, but does not reward them in the gap minimization. Readers interested in alternative model formulations can refer to the extensive previous literature on the subject (cf, Beged-Dov 1965, Benson et al. 1993, Czajkowsky and Jones 1986, Schmidt and Freeland 1992, Souder 1973 and 1978).

\subsection{Data Collection}

With the proposed framework came the realization that the first list of criteria had been on too aggregated a level. For meaningful analysis, the criteria needed to be quantified, along with the project contributions to the criteria. However, while quantitative data is readily available in traditional modeling applications (e.g., distances in a transshipment problem), it is a characteristic of R\&D that data are often qualitative and difficult to estimate. Data gathering is a major challenge in the implementation process. The predevelopment group had to address three interrelated issues.

First, the longest and hardest discussion became what should be included in the list of criteria. As a first step, this was done within the pre-development group. The list of eight general criteria-dynamics, economy, driver interface, comfort, safety, cost, quality and weight - was further specified into a list of 41 quantifiable criteria. For ex- 
ample, dynamics was broken down into "acceleration $0-100 \mathrm{~km} / \mathrm{hr}$, acceleration $0-4$ seconds under realistic conditions, acceleration $80-120 \mathrm{~km} / \mathrm{hr}$, cold start, hot start," and four others, which could all be quantified. The resulting list of 41 criteria then had to be cross-checked and confirmed with marketing as well as upper management.

In addition to identifying the dimensions, the pre-development team also had to decide about the relative importance of the criteria. They developed a set of weights for the eight general criteria because the engineers had a better intuition about relative importance at this aggregated level. All specific criteria within the same general criterion received an equal share of the general criteria weight. For example, the nine specific criteria within dynamics each received one ninth of the weight given to the general criteria of dynamics.

Second, the group had to quantify performance and to estimate the gap to target shortfalls. In order to achieve comparability across criteria, they decided to not use physical quantities (such as acceleration), but to construct an index with 100 indicating an agreed-upon target performance level for each criterion and 0 the low-end performance among BMW's direct competitors. Target levels of 100 represented an operationalization of the strategic mission "best powertrain 2000 ", and they typically exceeded current best-in-class performance. Based on this index, each engineer took responsibility for a group of criteria and estimated shortfalls from the target level of 100. Thus, a shortfall of zero meant that current performance was already at the target, and a shortfall of 100 indicated that current performance was at the low end (neither extreme case occurred). In a one-day workshop, the whole group discussed the performance estimates and shortfalls, and settled on agreed values.

Third, the contribution of each candidate project to each performance dimension had to be estimated. Each engineer produced a rough estimate for the projects $\mathrm{s} / \mathrm{he}$ was most familiar with. The resulting matrix of 80 projects and 41 criteria looked impossible to complete at first glance. However, as is demonstrated in Figure 1, the matrix turned out to be very sparse because each candidate project was mainly focused on one or two general criteria, affecting possibly $4-5$ specific criteria, including side effects. Thus, the number of parameters to be estimated was manageable. Another workshop served to achieve familiarity and agreement on the project contributions.

The product development team could not identify any significant market interactions - for example, benefit of one project in the market depending on the presence of a different project - and each project was technically feasible without requiring others as "enablers." Overall, only a small number of system interactions were present, and were mostly of the type "project A and project B exclude each other in the car". This is partially related to the architecture of a transmission and partially to the fact that projects were formulated in a focused manner - that is, targeted to specific transmission sub- 
systems. However, because the few extant system interactions were important in that they could significantly influence the optimal project portfolio, they were included in the model as constraints.

\subsection{Implementation within the Predevelopment Group}

The pre-development engineer with the broadest experience produced a small "trial matrix" for a few criteria and projects to get a feel for the criteria, and to evaluate whether it made sense to proceed with the approach. Next, the group manager presented the matrix as the definitive future decision base within his own group. He posed as a challenge to the group that the matrix had to be evaluated completely, forcing engineers to consider the possible negative or positive side effects of their proposed projects. At this point, he pulled 10 employees from within pre-development into the project (part time), and they held weekly meetings. From this time on, every new project idea had to be presented in the terms of the matrix.

When pre-development had the matrix about $60 \%$ completed, the authors visited the group for a second time, demonstrating how the mathematical program worked. At this point, several subtle concepts emerged and were discussed with the group. For example, the fact that projects could not be ranked because, depending on the level of resources available, a project could be chosen that would then make other, previously attractive projects unnecessary or unattractive. Much time was also spent playing with the model to test its behavior against the intuition of the engineers.

Over the next few weeks, e-mails were exchanged to clarify many of the difficulties involved in adapting the model to changes made by the group. It became clear, by way of the questions that were asked, that although the engineers understood the particular implementation of the model as discussed at the meeting, they had not acquired a general understanding of the methodology. In retrospect, this is certainly understandable given the level of complexity of the methodology being introduced.

The decision model was used for the first time to decide between improving the current four-speed automatic transmission and developing a new continuously variable transmission (CVT). Figure 3 shows the output of the model (with criteria, contributions and performance gaps) for the CVT project as it was visually presented to management.

Criteria are numbered along the horizontal axis ( 1 through 41 , numbers protect the confidentiality of the actual criteria used). The criteria are grouped into major areas of impact (e.g., criteria $1-9$ affect driving dynamics, as is indicated at the bottom of the Figure). The performance gaps along the criteria are indicated by the height of the bold line, i.e. the indices on the vertical axis represent the magnitude of an improvement 
need. A negative gap would indicate that current performance is more than sufficient (nowhere the case).

Project contributions to the performance gaps are indicated by shaded regions along the criteria. Negative contributions reflect the fact that the project reduces performance on some criteria. For example, the CVT transmission has noise problems, reducing performance on acoustics (criteria 19, in the "comfort" group). Critical problem areas are highlighted in the graph with bubbles and question marks. They direct management attention to criteria where the project leaves (or worsens) the gap between required and delivered performance. For example, a large problem exists with respect to space (criteria 39 , in the weight group), and with respect to manufacturing cost (criteria 41 , where the CVT does not address an urgent demand for cost reduction).

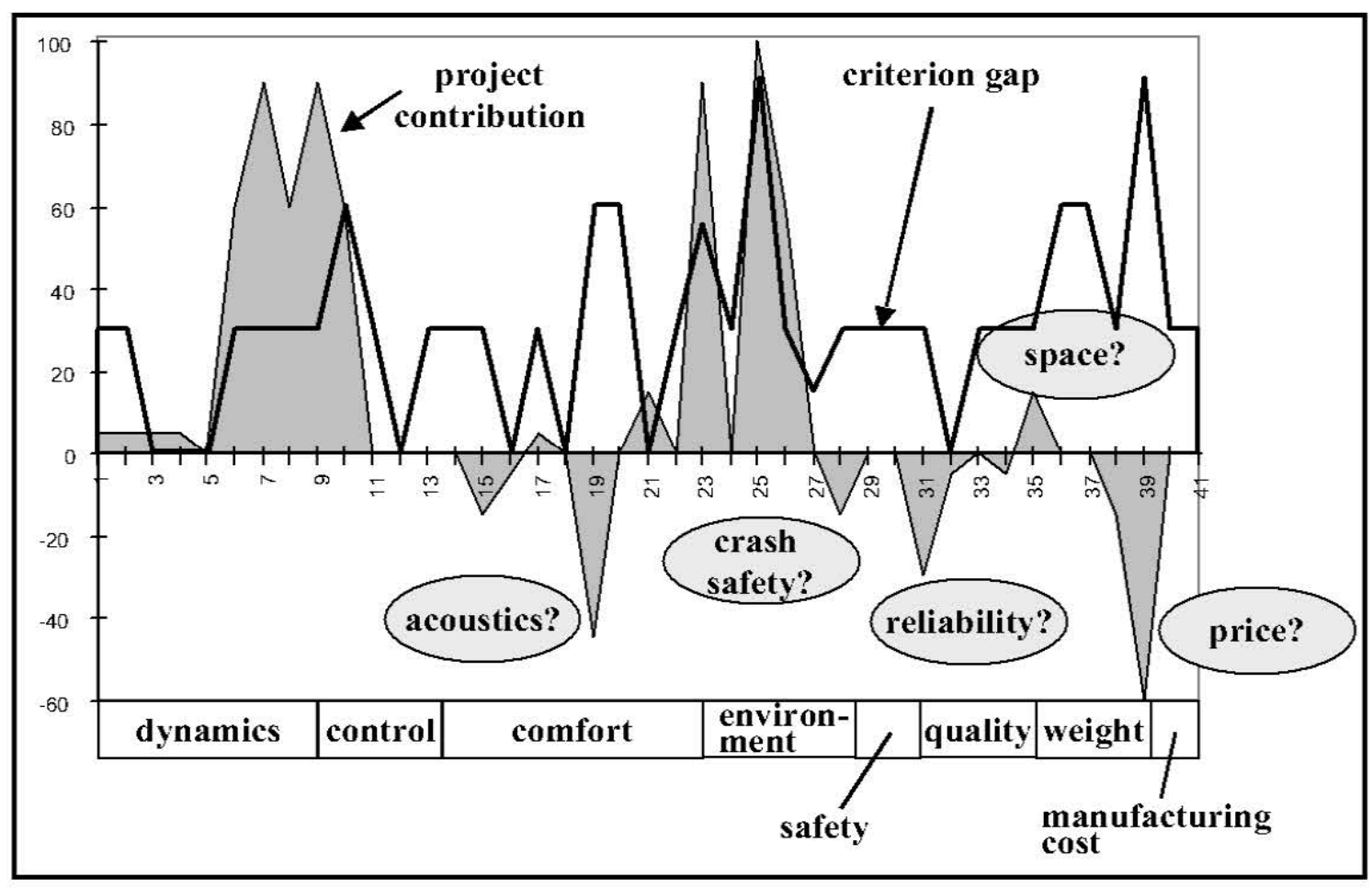

Figure 3: Proposal Chart for CVT Project

Management had a very limited ability to process even this level of complexity within one hour, but they appreciated the systematic consideration and weighing of all criteria, and thus they trusted and approved the proposed decision. Their decision was based entirely on the criteria, contributions and gaps. Resource usage and project interference were not used: they were viewed as not important for the choice between the four-speed upgrade and the CVT projects.

Thus, the matrix of criteria, contributions and gaps was successfully used as a decision support tool with upper management. The matrix is now becoming the standard in the transmission pre-development group, and a pilot is being applied in the engine group 
during March 1998.

\subsection{Diffusion to Other R\&D Sub-units}

Given that other technology groups within BMW struggled with similar issues, the predevelopment manager then introduced the concept of structured project selection into the entire drive train development organization. In communicating, he focused on the criteria, project contributions and gaps, rather than on the detailed quantitative method. The criteria were derived from the high-level criteria used in the company, and therefore, the other groups understood where they came from and were reasonably comfortable with the idea. Together they discussed again the list of criteria, and made corrections to get some of the numbers - that is, gaps and contributions - right. This way, the manager achieved acceptance from the other groups.

It has to be noted that the word "optimization" never left the pre-development group. External to his group, the manager emphasized the matrix of criteria, contributions and gaps, and would only casually mention the terms "resource constraints" and "project portfolio." This reflected a purposeful decision on his part to shield the rest of the organization from the mathematical program until he felt that it was understood and successfully implemented within his own group. The methodology was demonstrated at a company-wide exhibition event aimed at engineering management. The exhibition presented computer-based tools for improving the engineering process, and the model was included as a decision tool, along with other technical problem solving tools.

The pre-development manager approached upper management (up to the head of overall R\&D) with the model only after buy-in from other departments was achieved. The model was used in the form of the matrix of criteria, contributions and gaps to obtain project approval. The matrix was never presented to management in its full form-it is much too large to visually comprehend. Instead, the manager produced a subset of a few, obviously competing projects—such as new technology versus improvement to existing technology-across all criteria. In addition, he presented the gaps and contributions in graphical format similar to that presented in Figure 3.

\section{Observations and Discussion}

In this case study, we have seen all the typical characteristics of coaxing an organization into adopting a new, unknown methodology: a clear need for a new approach was identified, new ideas were brought into the organization, internal resistance within the sub-unit were overcome, the new ideas were adapted to local use and then were dif- 
fused to other, interdependent sub-units within the organization. In addition, the effort benefited from the competence and curiosity of the people involved, who were motivated to understand how the analytical model worked.

In spite of this success, the resource-constrained optimization feature of the model was not used by the organization. We argue that this partial implementation of the modeling methodology reflects both the limitations of the methodology and limitations of the technology transfer process. As Klein and Sorra (1996) recognize, “(a)n organization's failure to achieve the intended benefits of an innovation it has adopted may thus reflect either a failure of implementation or a failure of the innovation itself' (p. 1055).

\subsection{Limitations of the Mathematical Programming Model}

Analytical models are often incomplete and fail to capture adequately all relevant considerations (e.g., Schmidt and Freeland 1992). Moreover, full adoption of the methodology by the organization would have required significant additional resources in terms of man-hours invested to understand and modify the constrained optimization model. Therefore, the decision not to use the constrained optimization could be viewed as a rational, economic decision reflecting the highest benefit per effort invested. In this light, further attempts to improve the model could yield further adoption by the organization. Of course, the actual costs and benefits of full implementation are difficult to quantify and, in this case, no attempts were made to do so. Thus, it is difficult to fully justify this argument. Never the less, it is worthwhile to discuss the current limitations of the model, as we see them.

Structuring the decision problem as minimizing performance gaps using existing resources helped the pre-development group to think of how to use the matrix of criteria, project contributions and target gaps. In addition, it forced them to think about what was the driving factor or factors. Was there a "killer criteria" that was difficult to cover? Was it resources? Furthermore, the discussion of the model helped to drive the quanificution of the criteria, although the manager felt that they would have performed the quantification sooner or later, even without the model. The organization gained confidence that the comparison of projects with respect to reduction of total shortfall was insightful and robust - for example, a mis-estimation of a few parameters would not significantly distort the conclusion. However, they could not get to the same confidence level for the constrained optimization for three reasons; robustness, representation of uncertainty and complexity.

First, integer-valued constrained optimization problems tend to be non-robust. Small changes in parameters can result in a large change in the optimal portfolio, while producing only a small change in the objective function (here, weighted sum of shortfalls). 
This became apparent when, during the testing of the model, different project combinations resulted in the same total shortfall. As shortfalls, weights and contributions were subjectively estimated by the engineers, they tended to be whole round numbers (e.g., a shortfall is never 25.6 , but $10,20,30$, etc.). This reduced the robustness of the model: many portfolios clustered around similar objective function values, and small parameter changes could make the optimal portfolio tumble. Technically, this issue could be circumvented by introducing small perturbations in the criteria weights. However, such perturbations were seen as arbitrary, and could not overcome the group's skepticism resulting from this model behavior.

Second, the mathematical model would always make point recommendations, reflecting the difficulty in taking into account the full impact of uncertainty. ${ }^{2}$ In addition, this approach neglects the possibility of choosing a suboptimal portfolio because it is more robust in case of a contingency - in market demands, for example, or technical outcomes (Harrison and Van Mieghem, 1995). Given the combinatorial nature of the problem, sensitivity analysis proved of limited value for the constrained optimization, while it was easy to accomplish for the simple project comparisons adopted.

Third, the complexity of the model and limitations of the software implementation made it difficult for engineers to understand what happened inside the "black box" of the model. Even for a simple $3 \times 3$ matrix, they could not understand what the algorithm really did. In particular, as was explained above, multiple optimal solutions existed in small examples, and the algorithm stopped at different ones depending on the starting points. This alone was perceived as disconcerting, but in addition, not all the optimal solutions found made equally good sense, and it was hard to accept that the algorithm stopped without any further "common sense," based only on minimized total shortfall versus the targets across all criteria. The engineers were, in fact, learning a new modeling approach (mathematical programming), including interpretation of results, and a specific software program (What's Best running on top of Excel) at the same time.

In addition, changes in model fidelity often required changes in the structure of the model, not just its parameters. Thus, each change required getting help from the authors. More training than time permitted was needed to get the engineers to the point where they could use the model by themselves. This aspect of the problem would be difficult to fix without creating a very elaborate user interface.

Finally, the algorithm took a long time to find a solution in a few instances, where the problem was numerically ill conditioned (related to the round number estimates of the parameters described above). ${ }^{3}$ The model and the algorithms to solve it could have

A Monte Carlo simulation using Crystal Ball ${ }^{\mathrm{TM}}$ was developed to assess the impact of uncertainty. However, the group could not absorb this additional methodology in the time frame of the project. When the run-time problems occurred, the authors contacted What's Best to check for errors in the 
been modified to take advantage of particular structural characteristics of the problem. Although resource intensive, this model improvement could have helped to speed solution time in some problem instances. This would have required a significant increase in the level of abstraction of the analytical model. Since the group was at the limit of its resources anyway, the engineers did not have the slack to absorb further abstraction. When these problems occurred, the analytical approach was kept alive by a combination of persistence of the manager and intrinsic interest on the side of the engineers.

The pre-development manager summarized the requirements for a software program implementing an $\mathrm{R} \& \mathrm{D}$ project selection method as follows:

- The software needs to work quickly and easily with good graphics

- The software needs to be logically transparent-one must be able to infer the logic from examining simple examples

- Optimization features should be used only to the extent that they are of limited complexity and in instances where the problem to be solved is robust

- Above all, the model should be able to simply describe, summarize, and graph.

\subsection{Limitations of the Technology Transfer Process}

With respect to the implementation process, we observed that the manager's behavior played a very important role in the adoption of innovations. Here, the manager acted as a "boundary spanner" (Tushman, 1977) or "gatekeeper" (Allen and Cohen, 1969) in his role as the primary interface between the authors and the R\&D group. Thus, the extent to which the model was adopted was strongly influenced by purposeful actions of the manager.

However, the manager could only provide so much input into the process. Like the members of his group, he was unfamiliar with the proposed modeling methodology and so could not actually effect the transfer. Here, what was needed was intensive interaction with the authors, the diffusing agents. Strong ties had to be developed and sustained, both within the group-for purposes of developing and agreeing to the data required of the model — and between the group and the authors—-for purposes of understanding the modeling methodology. Here, the extent of implementation was strongly influenced by the limited resources of both the members of the group and the diffusing agents. A "window of opportunity" (Tyre and Orlikowski, 1992) existed where both the adopting organization and the diffusing agents were prepared to allocate sufficient resources to the transfer. Once the window was closed, further absorption and implementation of the model was unlikely.

algorithm. Ironically, there was a bug in the program at first (a brand new version was used), and 


\subsubsection{Weak Ties and The Role of the Manager as "Boundary Spanner"}

The manager of the pre-development group spanned three important organizational boundaries: (i) the extra-organizational boundary; (ii) the intra-subunit boundary; and (iii) the sub-unit to organization boundary (Tushman, 1977). He spanned the extraorganizational boundary through his on-going contacts with one of the authors. This contact allowed him to bring a new, innovative approach into the pre-development group: the mathematical program for project selection. The contact was utilized because he knew that the author would bring in an outside perspective on the problem: a perspective honed by research and contacts with other R\&D organizations.

He spanned the intra-subunit boundury as manager of the predevelopment group. Not surprisingly, there was resistance within the group, and had the manager not pushed the whole time, the approach would not have been pursued. First, the engineers in his group never related the fact that they did not get their project proposals approved to a lack of a structured approach. Second, they had limited time to invest in defining criteria and completing the matrix. This took time away from other activities. They were engineers who would rather design technology than fill in matrices. Third, the model itself added to the resistance because it required several leaps at once-quantifying criteria and understanding a new optimization methodology. This proved too much, especially in light of the software's previously mentioned shortcomings. Finally, there was the fear that they would become the slaves of the numbers the model would produce: "Let's say the number ' 115 ' comes out for one project, and someone says 'let's do this project, it has the biggest number attached to it,' but we don't like that project!"

Careful management helped to overcome this skepticism and mistrust. The group's manager left no doubt that the matrix was the future decision base within the group, committing himself to the importance of criteria, gaps and contributions. In order to calm the engineers' worries, it was clearly and repeatedly emphasized that the numbers were not the key, but producing the criteria and evaluating them, and discussing them with the experts in a more structured approach, to improve transparency. Everyone should understand what were the criteria, not just a few highlights. With this, the whole group would be more comfortable in making decisions and be able to sharpen their "gut feel."

The manager spanned the sub-unit to organization boundary through his interactions with the rest of the design organization. Because he understood the organization, criteria were chosen that were consistent with the high-level criteria used within the company. Thus, other groups were more comfortable with the matrix of criteria, contributions and gaps. Also, he never asked other groups for resources until the matrix was

only after the bug was fixed was it confirmed that these few problem instances were ill conditioned. 
demonstrated and they could convince themselves that the work made sense.

Finally, and most importantly, it should be noted that the manager filtered and adapted the innovation in diffusing it within his group and to the other groups. The manager decided to never use the word "optimization" outside of the pre-development group. Externally, only the terms "resource constraints" and "project portfolio" appeared. This filtering was fundamental in getting the matrix of criteria, contributions and gaps accepted by the rest of the organization (Thompson, 1967). Although the manager committed himself to the matrix of criteria, gaps and contributions, he never forced the group to adopt the optimization methodology.

\subsubsection{Strong Ties and The Resource Requirements of Technology Transfer}

As Von Hipple (1994) discovered, the information used in problem solving is "costly to acquire, transfer and use in a new location" and that when this "sticky information" resides in more than one location, "the locus of problem solving may iterate among these sites as problem solving proceeds." Thus, not surprisingly, many face-to-face and email exchanges were required to impart the many subtle and complex aspects of such methodologies and to address unforeseen problems that would arise as a result of some desired change to the model. These problem iterations consumed not only the resources of the potential adopter, but those of the diffusing agents as well.

Because resources are rarely committed indefinitely to such projects, a finite commitment of resources, both by the diffusing agents and by the potential adopters, created a "window of opportunity" within which as much progress as possible must be made on the adoption of the innovation. This project was no different in this respect. Both the academics and the pre-development groups budgeted time to the project before its inception. Deadlines were set and the project was halted once these deadlines were met. The window of opportunity closed and interactions between the group and the authors reverted back to their pre-project weak-tie form.

The manager of the pre-development group estimates that he got about $80 \%$ of what he had wanted from the effort. This $80 \%$ could be achieved based on project comparison along their contribution to shortfall reduction, without recourse to constrained optimization. The regular, monthly discussions of the structured approach motivated everybody to continue to think about how their projects would impact all of the criteria. The structure and its implementation as a mathematical programming model also provided an intcllcctual challenge for the cngincers. The model structurc helped cveryonc to understand the process of project choice better and thus led to higher transparency of decisions, or in other words, to more fact-based decisions: they learned to understand the matrix, the numbers and what they meant, and the importance of interference across projects. The value of this is evidenced by the fact that the first proposal they made 
using the matrix of criteria, contributions and gaps was immediately approved by upper management. Thus, the effort is counted as a success overall, and it will be further rolled out and developed.

However, the other side of the story is that $20 \%$ of the hoped-for results were missing. In spite of the fact that the manager believes that their current methods are too simplistic, the group is not using the model for constrained optimization (only for finding the projects with the highest weighted shortfall reduction). The group manager recognizes that their current use of the matrix of criteria, gaps and contributions does not take into account interdependencies among projects, nor that the projects compete for the same limited resources (mainly manpower). Initially, the group made the implicit decision that interdependencies and scarce resources did not matter much in the first step of the analysis. But resources are becoming an issue at the moment, so the group is looking at optimization with renewed interest. The manager feels that as the group becomes more familiar and comfortable with the matrix tool, they may start using it in a more sophisticated manner. This will depend, of course, on the continuing support of the group's manager and on the continuing involvement of the authors. Thus, as both the authors and the predevelopment group move on to other activities, it is quite likely that the predevelopment group will settle with the benefits already achieved.

\section{Conclusions and Outlook}

We have developed in this paper a structured model of $R \& D$ project selection which allowed the transmission pre-development group of BMW to move from a relatively unsystematic way of project selection to a structured approach. Successful adoption of the new method was achieved, starting with a clear need for the new approach, overcoming resistance through convincing skeptics, carefully supporting the learning of the people involved, emphasizing the qualitative insights, and consistently maintaining managerial attention. The new method was successfully used as a decision support for upper management. It helped the group to think through the decision criteria and to quantitatively compare projects according to their contribution. It led to higher transparency of the selection process and to more fact-based decisions.

It is an important insight that the organization adopted only those elements of the modeling method offering the highest benefit per effort invested. The adoption of the constrained optimization part would have resulted only in a marginal additional benefit while requiring significant additional resources. It is important for the modeler to accept that partial adoption in this sense may be the best possible outcome of the implementation effort for the adopter.

This is consistent with Hayes (1969) who observed that " ... the greatest impact of the 
quantitative approach will not be in the area of problem solving (...). Its greatest impact will be on problem formulation: the way managers think about their problems. (..) In this sense, results (...) contribute in a really significant way to the art of management." We add to this that it is not only the problem formulation that creates value, but also a quantitative analysis to the extent that it remains transparent to the host organization and is robust with respect to model perturbations-for example, from estimation or incompleteness.

We also report observations concerning the role of key boundary spanners and managers in the process of adoption. Boundary spanners are likely to play a critical role in the diffusion of models and methods from academia to industry. The thoughts and actions of these boundary spanners, especially if they are also managers, will have decisive effect on the extent to which the innovation is adopted. Finally, the adoption of any innovation takes the resources of both the diffusing agents as well as the potential adopters. When resources are budgeted, a window of opportunity is created within which the innovation must be understood, modified and adopted.

$R \& D$ project selection is an unstructured and difficult decision area, which has led to a widespread use of decisions based on "gut-feeling" in practice. One fundamental difficulty is related to the absence of quantitative data, which makes data collection and structuring itself a valuable effort. This article provides a detailed case example that, beyond data structuring, $R \& D$ project selection is amenable to quantitative analysis.

\section{References}

Allen, T. and S. Cohen, "Information Flows in Research and Development Laboratories," Administrative Science Quarterly 14, 1969, 12-19.

Arrow, K., "Classificatory Notes on the Production and Transmission of Technological Knowledge," American Economic: Review; Paper and Proceedings 52, 1969, 29-35.

Beged-Dov, A. G., "Optimal Assignment of R\&D Projects in a Large Company Using an Integer Programming Model," IEEE Transactions on Engineering Management EM-12, 1965, 138 - 142.

Benson, B., A. S. Sage, and G. Cook, "Emerging Technology Evaluation Methodology: With Application to Micro-Electromechanical Systems," IEEE Transactions on Engineering Management 40, 1993, 114 123.

Bodie, Z., A. Kane, and A. Marcus, "Optimal Risky Portfolios," Chapter 7 in: Investments, 2nd ed., Burr Ridge, 111.: Irwin 1993.

Brenner, M. S., "Practical R\&D Project Prioritization," Research Technology Management, September October $1994,38-42$.

Burnett, W. M., B. G. Silverman, and D. J. Monetta, "R\&D Project Appraisal at the Gas Research Institute," Operations Research 41, 1993, 1020-1032.

Cabral-Cardoso, C., and R. L. Payne, "Instrumental and Supportive use of Formal Selection Methods in 
R\&D Project Selection," IEEE Transactions on Engineering Management 43, 1996, 402 - 410.

Clark, K.B. and T. Fujimoto, Product Development Performance: Strategy, Organization, and Management in the World Auto Industry, Boston: Harvard Business School Press, 1991.

Cooper, R.G., S.J. Edgett, and E.J. Kleinschmidt, Portfolio Management for New Products, McMasters University, 1997.

Corbett, C. J., and L. N. Van Wassenhove, "The Natural Drift: What Happened to Operations Research?," Operations Research 41, 1993, 625-640.

Czajkowsky, A. F., and S. Jones, "Selecting Interrelated R\&D Projects in Space Technology Planning," IEEE Transactions on Engineering Management 33, 1986, 17 - 23.

Eisenhart, K. and B. Tabrizi, "Accelerating Adaptive Processes: Product Innovation in the Global Computer Industry," Administrative Science Quarterly 40, 1995, 84-110.

Fortuin, L., P. Van Beek, and L. N. Van Wassenhove, "Operational Research Can do More for Managers Than They Think," OR Insights 5, 1992, 3 - 8.

Fox, G. E., N. R. Baker, and J. L. Bryant, "Economic Models for R\&D Project selection in the Presence of Project Interactions," Management Science 30, 1984, 890 - 902.

Galbraith, J.R., Designing Complex Organizations, Reading, MA: Addison-Wesley 1973.

Granovetter, M.S., "The Strength of Weak Ties," American Joumal of Sociology 6, 1973, 1360-1380.

Hall, D. L., and A. Nauda, "An Interactive Approach for Selecting R\&D Projects," IEEE Transactions on Engineering Management 37, 1990, 126 - 133.

Hansen, M.T., "The Search-Transfer Problem: The Role of Weak Ties in Sharing Knowledge Across Organizational Boundaries," Administrative Science Quarterly 44, 1999, 82-111.

Harrison, J.M. and J. Van Mieghem, "Multi-Resource Investment Strategies: Operational Hedging in a Generalized Newsvendor Model," Stanford Working Paper, 1995.

Hayes, R. H., "Qualitative Insights From Quantitative Methods," Harvard Business Review, July August 1969, $108-119$.

Henderson, R.M. and I. Cockburn, "Measuring Competence? Exploring Firm Effects in Pharmaceutical Research," Strategic Management Joumal 15, 1994, 63-84.

Hess, S. W., "Swinging on the Branch of a Tree: Project Selection Applications," Interfaces 23, 1993, 5 12.

House, C. H., and R. L. Price, "The Return Map: Tracking Product Teams," Harvard Business Review, January-February 1991, $92-100$.

Klein, K.J. and J.S. Sorra, "The Challenge of Innovation Implementation," Academy of Management Review $21,1996,1055-1080$.

Krogh, L. C., J. H. Prager, D. P. Sorensen, and J. D. Tomlinson, "How 3M Evaluates Its R\&D Programs," Research Technology Management, November - December 1988, 10 -14.

Leonard-Barton, D. and I. Deschamps, "Managerial Influence in the Implementation of New Technology," Management Science 34, 1988, 1252-1265.

Leonard-Barton, D. and D.K. Sinha, "Developer-user Interaction and User Satisfaction in Internal Technology Transfer," Academy of Management Joumal 36, 1993, 1125-1139.

Liberatore, M. J., "An Extension of the Analytical Hierarchy Process for Industrial R\&D Project Selection and Resource Allocation," IEEE Transactions on Engineering Management EM-34, 1987, 12 - 18.

Loch, C. H., M. T. Pich, and C. Terwiesch, "Project Portfolio Management in Product Development," Proceedings of the 4th EIASM International Product Development Conference, May 1997, 517 - 532.

Mitchell, G., The Practice of Operational Research, Chichester: Wiley 1993. 
Nelson, R. R., and S. G. Winter, An Evolutionary Theory of Economic Change, Belknap Harvard 1982.

Pich, M. T., and S. Stout, "The Structure of Attention: Centrality and Bottlenecks in the Diffusion of Innovations," INSEAD Working Paper 1997.

Roussel, P. A., K. M. Saad, and T. J. Erickson, "The R\&D Portfolio," in: 3rd Generation R\&D, HBS Press $1991,93-122$.

Schmidt, R. L., and J. R. Freeland, "Recent Progress in Modeling R\&D Project-Selection Processes," IEEE Transactions on Engineering Management 39, 1992, 189 - 199.

Sharpe, P. and T. Keelin, "How Smith Kline Beecham Makes Better Resource-Allocation Decisions," Harvard Business Review, March-April 1998, 45-57.

Souder, W. E., "Analytical Effectiveness of Mathematical Models for R\&D Project Selection," Management Science 19, 1973, 907 - 923.

Souder, W. E., "Project Selection, Planning, and Control," in: Moder, J. J., and S. E. Elmaghraby (eds.): Handbook of Operations Research, New York: Van Nostrand Reinhold, 1978.

Szulanski, G., "Exploring Internal Stickiness: Impediments to the Transfer of Best Practice within the Firm," Strategic Management Journal 17, 1996, 27-43.

Thompson, J., Organizations in Action, New York: McGraw-Hill 1967.

Tushman, M. L., "Special Boundary Roles in the Innovation Process," Administrative Science Quarterly $22,1977,587-605$.

Tyre, M.J. and W.J. Orlikowski, "Windows of Opportunity: Temporal Patterns of Technological Adaptation in Organizations," Working Paper, 1992.

von Hippel, E., "Sticky Information and the Locus of Problem Solving: Implications for Innovation," Management Science 40, 1994, 429-439.

Wheelwright, S. C, and K. B. Clark, "Structuring the Development Funnel," Chapter 5 in: Revolutionizing Product Development, The Free Press, 1992, 111 - 132.

Winter, S., "Knowledge and Competence as Strategic Assets", in D. Teece (ed.), The Competitive Challenge-Strategies for Industrial Innovation and Renewal, Cambridge: Ballinger, 1987, 159-184.

Yap, C. M., and W. E. Souder, "A Filter System for Technology Evaluation and Selection," Technovation $13,1993,449-469$.

\section{APPENDIX: MODEL FORMULATION}

This is a standard mixed integer linear program (see $[2,5]$ ), with the added feature that projects can be targeted at the different transmission types, and system constraints hold only within types. This allows product line variety across types.

Parameters: $\quad i=$ project index,$j=$ target dimension index,

$k=$ transmission type index with $k=1, \ldots K$.

$G_{k j}=$ gap to target for transmission type $k$ on target dimension $j$

$b_{i j}=$ contribution of project $i$ to dimension $j$ (same for all $k$ )

$c_{i}=$ resource requirement (in Person Years) of project $i$

$C=$ available development capacity (in Person Years)

$w_{k j}=$ importance weight of dimension $j$ for transmission type $k$

$v_{k}=$ importance weight of the transmission type $k$.

$E_{k j}=$ excess of target fulfillment for transmission type $k$ on dimension $j$. This variable is a resulting accounting variable computed endogenously (see below). 
Decision Variables:

$x_{i}=1$ if project $i$ is chosen and $\theta$ if not

$x_{k i}=1$ if project $i$ is targeted at transmission type $k$ and $\theta$ if not

$S_{k j}=$ remaining shortfall to fulfilling gap for type $k$ on dimension $j$ after all project contributions.

Minimize: $\quad \sum_{k} v_{k} \sum_{j} w_{k j} S_{k j}$

subject to: $\quad$ 1. $E_{k j}=\sum_{i}\left[b_{i j} x_{k i}\right]-G_{k j}+S_{k j} \quad \forall k$

2. $S_{k j}, E_{k j} \geq 0 \quad \forall k, j$

3. $x_{k i}, x_{i} \in\{0,1\} \quad \forall k, i$

4. $\Sigma_{k}\left[x_{k i}\right] \leq K x_{i} \quad \forall i$

5. $\sum_{i} c_{i} x_{i} \leq C$

6. $M-M x_{k n} \geq \sum_{m \in \mathfrak{S}} x_{k n}$ (example, for a specific $k$ and $n$ )

7. $\sum_{m \in \mathfrak{I}} x_{k m} \leq 1$ (example, for a specific $\mathfrak{S}$ and $k$ )

The objective function is the total weighted shortfall against the targets over all dimensions and transmission types. Constraints 1 and 2 are key accounting constraints necessary because the client does not want to "reward" an over-fulfilment of any target dimension. At the same time, they keep the problem linear and thus more easily solvable. The sum in constraint 1 is the total contribution to target dimension $j$ for transmission $k$. If it is larger than the target gap, then the excess is positive, and shortfall can be left at zero. If the total contribution is smaller than the gap, then shortfall must be set positive in order to fulfill constraint 2. Since shortfall is minimized, this will prompt an attempt to introduce additional projects to reduce the necessary level of shortfalls. Thus, the $S_{k j}$ are formally decision variables, but have only the role to prevent the optimization algorithm from pursuing target overfulfilments.

Constraint 3 specifies the integer constraints (projects are either pursued or not), and constraint 4 expresses that a project can only be targeted at any transmission type if it is pursued in the first place. Constraint 5 ensures that the set of projects pursued does not require more than the available development capacity.

Constraints 6 and 7 are examples of projects mutually excluding one another. In constraint 6 , project $n$ cannot be done at the same time as any of the $M$ projects in set $\Im$. Thus, if any $x_{k n n}$ is chosen, then $x_{k n}$ must be zero to fulfill the constraint; conversely, if $x_{k n}=1$, then all the $x_{k n}$ 's must be zero to fulfill the constraint. Similarly, in constraint 7 all the projects in the set are mutually exclusive, thus at most one of them can be chosen larger than zero. In our case, we had ten constraints of the type of 6 and 7 . These constraints only hold within a transmission type, thus variety across types is possible. 